\title{
Performances evaluation of a hydraulic structure using the reliability methods
}

\author{
A Hebbouche ${ }^{1}$, F Belheouane ${ }^{2}$, $S$ Bennoud ${ }^{2 *}$ \\ 1. École Nationale Supérieure d' Hydraulique, MVRE, Blida, Algeria \\ 2. University of Saad Dahlab, Blida, Algeria
}

\begin{abstract}
The exploitation of the structures (planes, engines) and of the infrastructures (dams, nuclear thermal power stations) with a very high cost of realization and a significant working life must be done with a risk of damages and failures reduced and controlled. This paper proposes a case study for the risk assessment of a hydraulic structure under random contingencies effects by using reliability and vulnerability measures. The reliability which can be defined as the probability that the system will remain in a non-failure state, and vulnerability which represents the system's susceptibility to failure have been investigated in this paper. Our study provides a helpful approach for an effective utilization and combination of reliability and vulnerability indices to improve the functioning and security, and to take an adequate decision on the system state.
\end{abstract}

\section{INTRODUCTION}

In the last years, important efforts have been developed on the field of the risks management and their analysis for possible destruction of critical technological and engineering systems. Several concepts, such as reliability and vulnerability, can be taken into account to manage these risks in desired systems. It should be evident that a reliable structure (or system) represents more advantages. Contrary, a vulnerable structure (or system) represents serious disadvantages on terms related to security and costs. The concepts of reliability and vulnerability are both associated to ensure the functioning of critical systems and increase their security level, and their determination is necessary to prevent future potentially destructive actions [1,2].

Various previous works have mentioned the importance of each of these concepts separately [1-8], but recent researches demonstrate that both concepts should be taken simultaneously into account to improve characteristics and security level of structural systems [9-13]. So, it is very important to determinate how to use the reliability and vulnerability analyses for making decisions on critical infrastructures or structures. The reliability can be defined as the probability that the system or more of its elements functions (it is the ability of the studied system to ensure the desired operations in continuity). Vulnerability, on the other hand, can be defined as the likely damage of a failure event (it is the level of the system degradation under random failures effects, which make the system out of service).

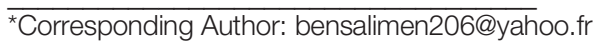


Several approaches, from analytical to computational models, are possible to evaluate the reliability and vulnerability of the structural systems.

This paper discusses some of the characteristics that influence the reliability and vulnerability of a concrete structure, influences that can be related to structure (dimensions, materials properties), nature (environmental parameters, seism) or others attributes (methods, means of calculations, human errors, modeling of the physical phenomena).

To ensure the safety of the structures by a robust design and an adequate maintenance in exploitation, it is necessary to take into account the origins of these influences and to reduce their adverse effects by the use of techniques and adapted means, the improvement of knowledge or by their quantification.

Concrete structure can be affected by seismic loads and earthquake effects. Moreover, damages provoked under these risks to this structure, especially to the dams, can increase the extent of the potentially catastrophic consequences in terms environmental, economic and of human lives losses $[1,5]$. In this context, several approaches can be used; one uses either the deterministic approach, or the semi- probabilistic approach or then the probabilistic approach [14-19]. The probabilistic approach gathers three categories of methods which are the methods of analysis to determine the statistical characteristics of the mechanical answer (density of probability), the methods of sensitivity analysis and the reliability methods based on the evaluation of the failure probability with respect to a given scenario.

The reliability methods applied on the concrete structure field have received a particular attention during these last years because of the relevance of the probabilistic assessment of the input data $[9,16-19]$. This method may therefore be used as a helpful tool to help engineers and exploiters understand how various parameters and proprieties will affect the dam behavior under service and how this dam can support potential damages in the future.

This paper provides a robust application of one of the probabilistic approaches (reliability methods) to calculate reliability and vulnerability indices and improve the dam performance under both indices criteria.

\section{METHOD}

The Probabilistic Risk Assessment (PRA) is a method allowing to evaluate uncertainties, performance, reliability and the vulnerability of a system in order to set up measurements of mitigation of the risk in function of performance objectives and safety.

In order to evaluate the vulnerability of structure using curves of fragility, a representative series of accelerograms adequate to the studied site spectrum must be considered. The band of the responses spectra of the obtained accelerograms must be compatible with the uniform spectrum of the area for certain range of periods.

Two methods are available in order to obtain compatible accelerograms: the selection of historical accelerograms which consists in calibrating recordings of real seisms to make them compatible for certain range of periods, and the synthetic generation of accelerograms (it is often necessary to generate and use synthetic ground motions compatible with the uniform spectrum of risks). One of the important parts of PRA method consists to define several limits states $(L S)$ of damage in order to describe the system performance. 
Once the limits states $(L S)$ and accelerograms are obtained, the curves of fragility can be evaluated.

The curves of fragility are a probabilistic tool of the evaluation of the seismic vulnerability of a structure. These curves are an essential component of a probabilistic analysis of the seismic risks. They make it possible to take into account the randomness effects of seism and uncertainties connected to the structure properties.

The fragility is given by:

$$
F r=P[L S \mid I S=y]
$$

where $(L S)$ is the limit state of damage, $(I S)$ are the measurement of the seism intensity and $(y)$ is the condition carried out for the measurement of the seism intensity.

The factor of safety is defined as:

$$
F S=C s / D s
$$

where $(C s)$ is the system's capacity and $(D s)$ is its demand.

In our case study, the capacity and demand depend to seismic loads related to natural phenomena which are considered as random uncertainties. However, the factor of safety (FS) will also be uncertain and given as a random variable.

If it is supposed that the $(L S)$ of a structure is related to its structural capacity $(C s)$ and that the measurement of the seism intensity $(I S)$ is dependent to the structural demand $(D s)$, the assessment of failure probabilities is related to the performance function of the structural system.

The fragility can also be described, for this case, as a probability of failure $\left(P_{f}\right)$ which can be obtained by means of structural reliability analysis and given by the equation (3).

$$
F r=P_{f}=P(D s / C s>=1)
$$

As can be seen in equation (2), (Ds) and (Cs) are defined as functions of probability density of the random variables and the obtained equation of failure probability is also object of uncertainties. Thus, the determination of the fragility constitutes in evaluating a multidimensional integral. Therefore, the application of the reliability methods is an adequate and an efficacy tool to calculate the failure probability.

The integral form of this equation can be solved by various methods such as FORM (First Order Reliability Method)), SORM (Second Order Reliability Method)), MCS (Monte Carlo Simulation)) or LHS (Latin Hypercube Simulation).

The fragility is thus modeled by a log-normal function of the following form:

$$
F_{R}(y)=\Phi\left[\frac{\ln \left(y / m_{R}\right)}{\beta_{C}}\right]
$$


where $[\Phi]$ is the standard normal distribution, $m_{R}$ is the median capacity, $y$ is the variable of demand and $\beta c$ is the combined uncertainty of the capacity given by the following equation:

$$
\beta c=\sqrt{\left(\beta_{R R}^{2}+\beta_{R U}^{2}\right)}
$$

where $\beta_{R R}$ and $\beta_{R U}$ are respectively the random uncertainty and epistemic uncertainty.

According to the equation (3), it can be noted that it is necessary to model the demand and/or seismic capacity to carried out analytical curves of fragility. The failure probabilities analysis is strictly depended and related to the reliability index $(\beta)$ which can be described as a measure of safety with respect to over passing the limit state. A standard reliability measure may be chosen to be the reliability index. The reliability index makes it possible to obtain an approximation of the probability of failure. There exists in the literature several types of the reliability indices [16-19]. The relation between the probability of failure and the generalized reliability index is given, under certain conditions, by the following formula:

$$
\beta=\Phi^{-1}\left(P_{f}\right)
$$

where $\beta$ the reliability index and $\Phi$ the standard normal cumulative distribution.

The first stage consists to select a series of representative accelerograms of the considered site.

Following the selection of accelerograms, a model of the structure must be developed and this one must be sampled. The probabilistic sampling of the model makes it possible to take into account various uncertainties. The uncertainties parameters must thus be defined like random variables and a function of probability density must be assigned for each uncertainty parameter. The LHS method implies to sample $\mathrm{N}$ values of the p parameters. The function of probability density of each parameter is thus divided into $\mathrm{N}$ intervals equiprobable and an individual value is selected by chance in the interval. The $\mathrm{N}$ values obtained for each parameter are then coupled by chance with the other variables. One thus obtains $\mathrm{N}$ samples of the numerical model. The next stage consists to determinate the probabilistic models of the seismic demand (PSDM (Probabilistic Seismic Demand Model)). Each sample of the structure is coupled with an accelerogram, not calibrated, and a nonlinear temporal dynamic analysis is carried out for each sample. The maximum responses of critical components of the structure are measured.

The brief replies are given according to the limits states of damage established. Once the seismic demand is given, it is necessary to specify the capacity or the limit state of damage. Finally, the curves of fragility can be developed and evaluated.

\section{PROBLEM MODELING}

Concrete is a composite construction material known as being a mixed paste of the following three parts: cement, water and aggregates.

Any dams can be exposed to several types of risk (seisms, movements or landslides, defects of maintenance and control, and risings), of which it is advisable to evaluate, according to the local circumstances, the frequency and the importance of these loads or variations. 
The studied dam situated on the west of Algeria is considered as a case study. A schematic representation of the dam model is shown in figure (1).

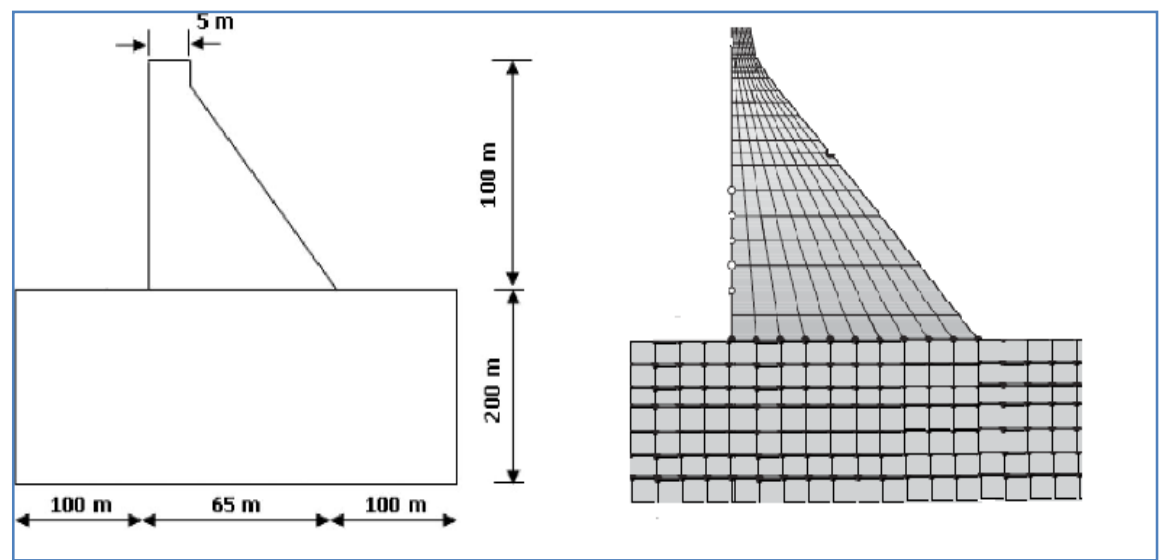

Fig 1: Problem description and mesh generation.

The considered dam is a concrete gravity-type dam with $100 \mathrm{~m}$ of height. It has a trapezoidal shape with a crest of $5 \mathrm{~m}$ in width and $182 \mathrm{~m}$ in length, the thickness at the base is $65 \mathrm{~m}$ and the foundation thickness is of $200 \mathrm{~m}$. the mesh generation related to the studied problem is performed with 1550 nodes and 1234 isoparametric 2D rectangular elements with four nodes, see figure 1 .

\subsection{Materials properties}

The materials properties of the studied structure are given in table 1 .

Table 1: Properties of the structure's materials.

\begin{tabular}{ll}
\hline Materials properties & \\
\hline Mass density of water & $1000\left(\mathrm{~kg} / \mathrm{m}^{3}\right)$ \\
Mass density of concrete & $2500\left(\mathrm{~kg} / \mathrm{m}^{3}\right)$ \\
Young's modulus of dam & $31(\mathrm{GPa})$ \\
Poisson's ratio of dam & 0.2 \\
Young's modulus of foundation & $60 \mathrm{GPa}$ \\
\hline
\end{tabular}

Several conditions and assumptions are considered to get the adequate model to the selected case.

\subsection{Random variables}

The random variables used are assumed to be statistically independent. The chosen variables (used and inspired from 15), their limits and their distribution probability are given in the next table. 
Table 2: Selected random variables.

\begin{tabular}{lll}
\hline Random variables & Probability distribution & Range (min, max)/ unit \\
\hline Young modulus of concrete & Uniform & $(31.2 ; 36) 10^{3} \mathrm{MPa}$ \\
Young modulus of soil & Uniform & $(40 ; 80) 10^{3} \mathrm{MPa}$ \\
Cohesion & Uniform & $(0.145 ; 0.435) \mathrm{MPa}$ \\
Dilation angle of foundation & Uniform & $(27 ; 33)$ degrees \\
Friction angle & Uniform & $(34 ; 45)$ degrees \\
Compressive strength of concrete & Normal & $(35 ; 4.8) \mathrm{MPa}$ \\
\hline
\end{tabular}

\section{RESULTS AND DISCUSSIONS}

Within the framework of this study, the random variables whose their value could have a significant impact on the seismic response of the structure will be identify and definite in form of parameters associated with densities of probability. These parameters are reported in table 2 which shows the six modeling parameters considered in this study and their associated probability density functions.

Seismic hazard in terms of spectral acceleration has been estimated based on the previous studies related to the site of northern Algeria [1, 5, 8, 15]. The main parameters considered for the choice of these recordings are magnitude, epicentral distance, peak ground acceleration (PGA) and peak ground velocity (PGV).

The accelerograms were simulated for two magnitudes and two fault distance ranges each: 4-10 and 20-45 km for M6; and 5-11 and 23-47 km for M7;4.

The earthquake analyses of the dams were performed. The records obtained less than 10 $\mathrm{km}$ to epicenter were related to near-fault accelerograms and the other records more than 10 $\mathrm{km}$ to epicenter were related to far-fault accelerograms.

Figure (2) illustrates an example of accelerogram acceleration and response spectra obtained for a magnitude value of $(7,4)$, a distance from the source of $5 \mathrm{~km}$ and peak acceleration (PGA) of $0.15 \mathrm{~g}$.

Preliminary analyses were carried out to determine the limits states of potential damages. These analyses will consist to identify the critical zones of the structure and permit to determinate the displacements and maximum/minimum principal stresses.

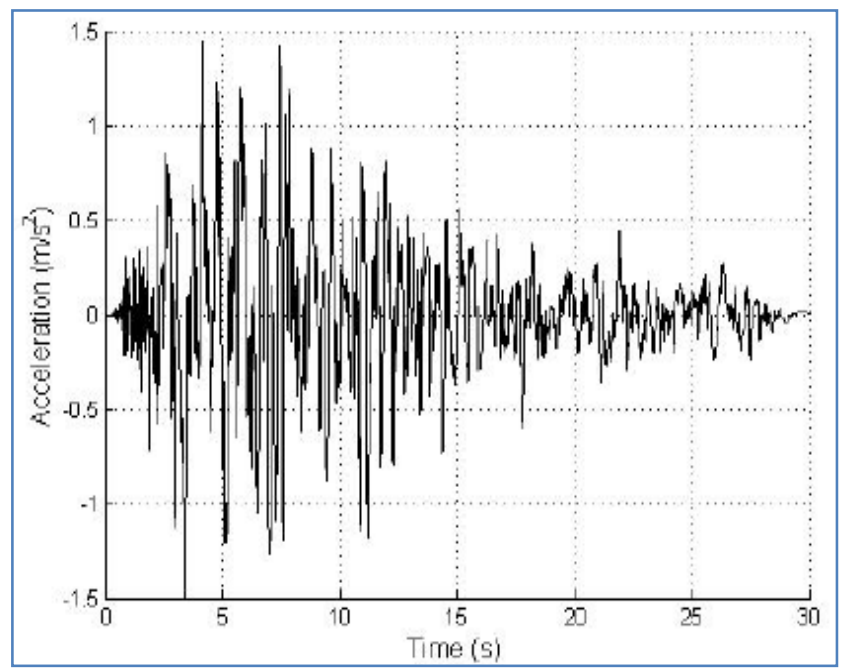

(a) 


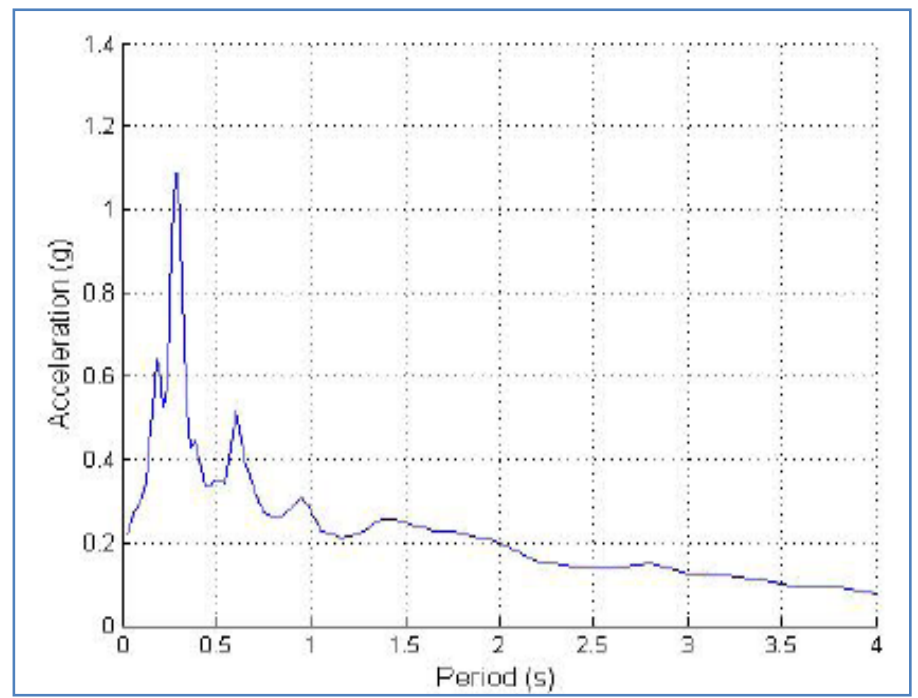

(b)

Figure 2: The accelerogram: (a) acceleration and (b) response spectra.

Nonlinear dynamic analyses were carried out using the SAP2000 software. They are performed to study the seismic performance of considered dam under various seism intensities. The results showed that a concentration of tensile stress occurs where there is a sectional change and in particular at the neck of the dam. From the above analysis, several domains were observed (elastic domain, inelastic domain) in which the plastic formation and plastic deformation in the elements can be evaluated. These domains are characterized by the limits of shear force (elastic limit, ultimate limit) and limits of displacements. However, three limits are considered to quantify the structural damage states in this study. Each limit state is associated to several damage levels. The levels of considered damage are defined and reported from the data presented in [15]. It can be shown in table 3.

Table 3: Limit states values for records more than $10 \mathrm{Km}$.

\begin{tabular}{|c|c|c|c|}
\hline Damage state & Moderate & Extensive & Complete \\
\hline $\begin{array}{l}\text { Category of damage } \\
\text { notion }\end{array}$ & $\begin{array}{l}\text { small rate of damage } \\
\text { in the structure }\end{array}$ & $\begin{array}{l}\text { important rate of } \\
\text { damage-cracks } \\
\text { apparition }\end{array}$ & $\begin{array}{l}\text { great rate of damage } \\
\text { heavy damage }\end{array}$ \\
\hline $\begin{array}{l}\text { Limit threshold } \\
\text { Rule }\end{array}$ & $\begin{array}{l}\text { Lim1 } \\
\text { (Delastic/Eelastic) }\end{array}$ & $\begin{array}{l}\operatorname{Lim} 2 \\
(\text { Delastic/celastic) < } \\
\operatorname{Lim} 2< \\
\text { (Dplastic/Eplastic) }\end{array}$ & $\begin{array}{l}\text { Lim3 } \\
\text { (Dplastic/Eplastic) }\end{array}$ \\
\hline $\begin{array}{l}\text { Material failure - } \\
\text { concrete (at the neck } \\
\text { of the dam) - MF }\end{array}$ & $1.46 \mathrm{MPa}$ & $2.6 \mathrm{MPa}$ & $3.75 \mathrm{MPa}$ \\
\hline $\begin{array}{l}\text { Displacement at the } \\
\text { top of the dam - DTop }\end{array}$ & $10.2 \mathrm{~mm}$ & $37.3 \mathrm{~mm}$ & $20.4 \mathrm{~mm}$ \\
\hline
\end{tabular}


The fragility curves are constructed by varying the seismic intensity parametrically to ten intensity values for a total of 160 simulations. For each damage level associated with a selected limit state, ten point estimates of the fragility, corresponding to ten spectral acceleration values, are carried out, see figure 3. Seismic fragility was evaluated for ten levels of seismic intensity ranging from 0.2 to $2 \mathrm{~g}$.

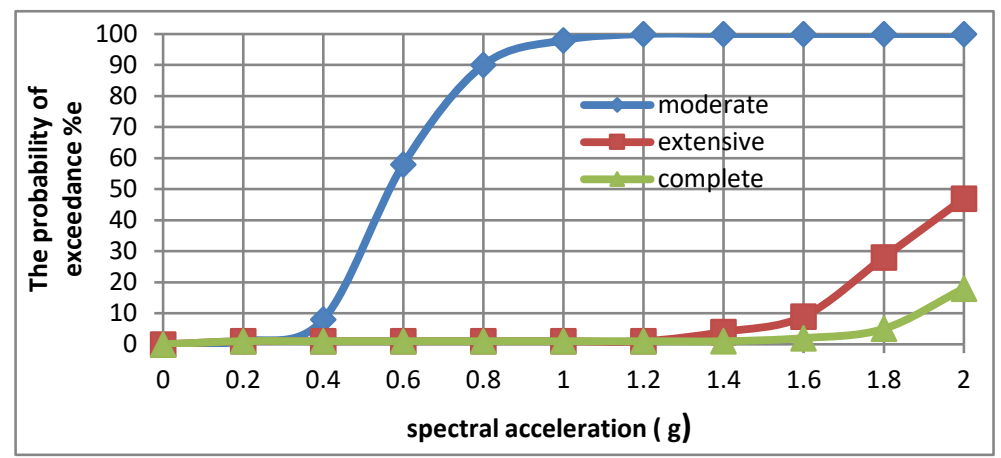

Fig. 3: Seismic fragility curves for Tensile stress MF at the neck of dam.

Figure 3 shows the evolution of seismic fragility curves corresponding to the case of limit state for Tensile stress MF at the neck of dam which related to concrete failure under effects of a accelerogram with height seismic intensity and epicentric distance more than $10 \mathrm{Km}$. The probability of exceedance for moderate, extensive and complete damage is, respectively, $100 \%, 47 \%$ and $18 \%$ for a spectral acceleration of $2 \mathrm{~g}$. The probability of exceedance is relatively low for complete damage decreases when the epicentric distance increases, see figure 4.

\subsection{Damage probabilities}

Using the cumulative probabilities functions, the damage probabilities values can be derived for each of the considered damage categories (three categories in this case study: moderate, extensive, complete) and in addition for the cases of slight damage and no damage.

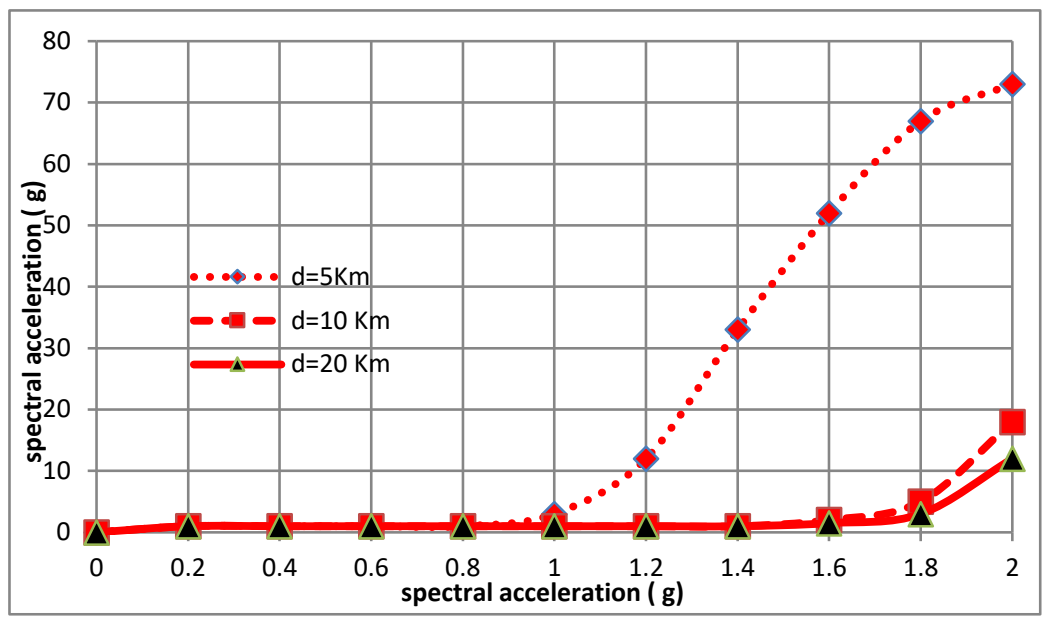

Fig. 4: Seismic fragility curves for Tensile stress MF at the neck of dam for different epicentric distances. 
Figure 5 shows the damage probability histograms provided for different epicentric distances and applied for the same intensity (M7.4). it can be noted that when the epicentric distance is less than $10 \mathrm{Km}$, the most important probability represents the extensive damage category with an average value of $(42 \%)$, whereas for ground motions characterized by epicentric distance more than $10 \mathrm{Km}$, the most important probability represents the moderate category with an average value of $(59.3 \%)$.

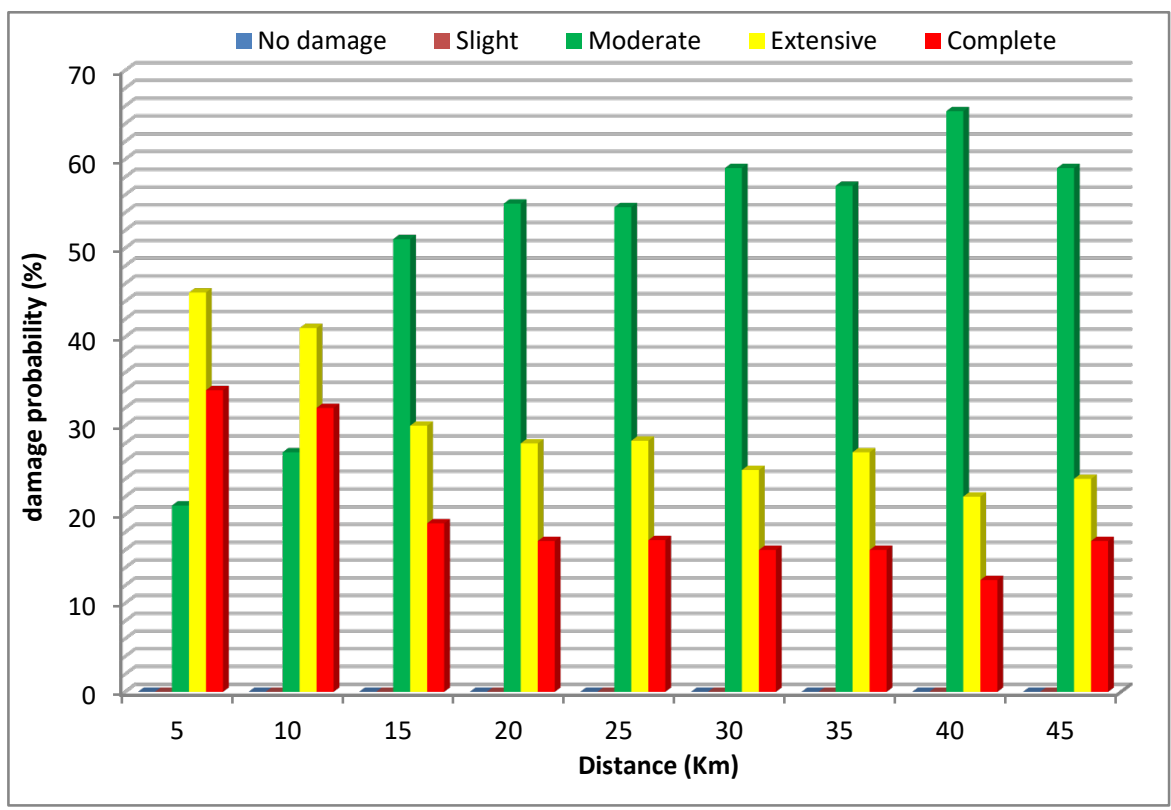

Fig. 5: Damage probability for tensile stress at the neck of dam.

A global sensitivity analysis is performed in order to evaluate the influence of some parameters.

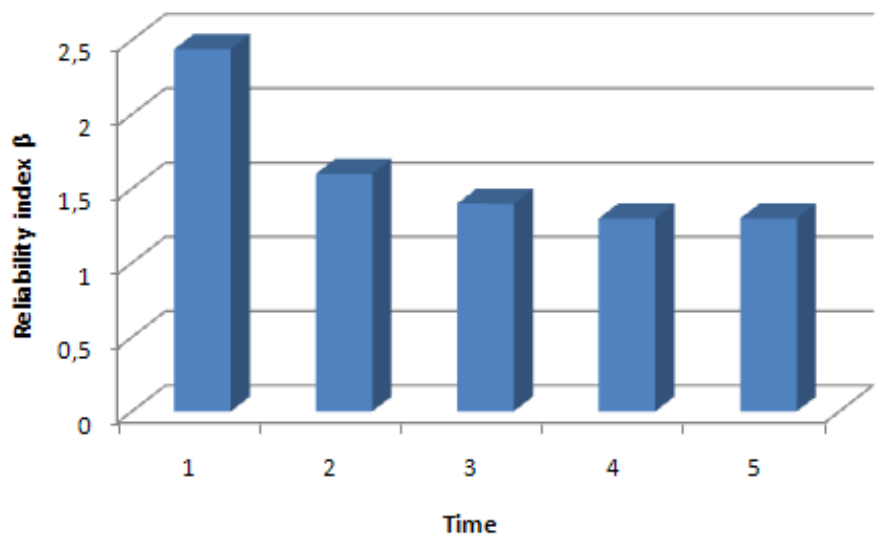

(a) 


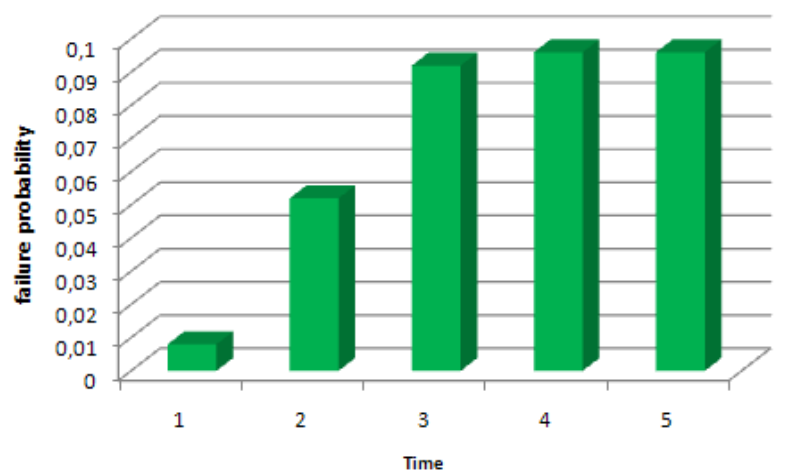

(b)

Fig 6: Evolution in time of the reliability index and probability of failure

Finally, the principal objective of this study is directed to the evolution in the time of reliability relative to the defined failures modes, like with the role played by each variable in this evolution. The method of reliability is used to determine the factors of importance and the probability of failure via the calculation of the reliability index. Figure (6) illustrate the evolution in time of the reliability index and probability of failure. The probabilities of failure increase quickly between periods $1-3$, then a little less quickly between periods $4-5$, they are varied from $0.73 \%$ to $9.6 \%$. Concomitantly, the indices of reliability $\beta$ decreases from 2.4 to 1.3 over the period $1-5$.

\section{CONCLUSION}

The present study focuses the safety evaluation of dams under service. The paper introduces reliability and vulnerability as decision-support parameters for structure safety analyses and seeks to valorize the importance of the relation between both terms. To evaluate the vulnerability and reliability of the considered dam, sixteen samples were obtained with the LHS method and were simulated for ten levels of seismic intensity by calibrating the accelerograms according to the acceleration of point to the dam neck; six random parameters were considered. The limit state being studied was and tree level of damage was considered. The reliability and vulnerability of any structure or infrastructure is thus a decisive factor not only in terms of investment costs, but also in terms of security, to ensure operation and function of the desired system. Consequently, the above aspects need to be more than a quantitative probability calculation or a qualitative indices related to the state of system functioning. The probabilistic methods are very useful since they evaluate the reliability and the vulnerability of a structure for all the range of loadings has which the structure will be subjected. This study validates that the development of curves of fragility for the seismic vulnerability of a concrete dam using a sampling procedure, such as LHS method is adequate, simple of use and offers excellent results. 


\section{REFERENCES}

[1] A. Hebbouche, M. Bensaibi, H. Mroueh, Seismic Fragility and uncertainty Analysis of Concrete Gravity Dams under NearFault Ground Motions, Civil and Environmental Research, 2013, Vol 5: 123-129.

[2] Y. Ghanaat, P. S. Hashimoto, O. Zuchuat et R. P. Kennedy, Seismic fragility of Muhlberg dam using nonlinear analysis with Latin Hypercube Simulation. In 31st Annual United States Society on Dams Conference, 2011: 1197-1212.

[3] W Kröger, E Zio, Vulnerable systems' (Springer Science \& BusinessMedia, USA, 2011.

[4] J. Ghosh, J. E. Padgett et L. Duenas-Osorio, Surrogate modeling and failure surface visualization for efficient seismic vulnerability assessment of highway bridges. Probabilistic Engineering Mechanics, 34:189-199, 2013.

[5] A. Hebbouche, M. Bensaibi, H. Mroueh, Seismic Risk Analysis of Concrete Gravity Dams under NearFault Ground Motions, Applied Mechanics and Materials, 2013, Vols. 256-259: 2240-2243.

[6] X Guo, D Dias, C Carvajal, L Peyra, P Breul, Reliability analysis of embankment dam sliding stability using the sparse polynomial chaos expansion. Engineering Structures 2018;174:295-307.

[7] J Ji, C Zhang, Y Gao, J Kodikara Reliability-based design for geotechnical engineering: an inverse FORM approach for practice. Computers and Geotechnics 2019; 111:22-31.

[8] Belheouane F I and Bensaibi M; "Seismic Vulnerability Index for Reinforced Concrete Construction in Algeria", Advanced Science Letter, 2012, 13(1):364-368.

[9] E Quagliarini, M Lucesoli, G Bernardini, Rapid tools for assessing building heritage's seismic vulnerability: a preliminary reliability analysis, Journal of Cultural Heritage, 2019, $39: 130-139$.

[10] A.T Murray, T Grubesic, Critical infrastructure: reliability and vulnerability' (Springer Science \& Business Media, USA, 2007.

[11] MA Hariri-Ardebili, Risk, Reliability, Resilience (R3) and beyond in dam engineering: A state-of-the-art review. International journal of disaster risk reduction, 2018, 31: 806-831.

[12] Thomas Rodding Kjeldsen, Dan Rosbjerg, Choice of reliability, resilience and vulnerability estimators for risk assessments of water resources systems, Hydrological Sciences, 2004, 49(5):755-767.

[13] D I Blockley, J Agarwal, J T Pinto, et al, Structural vulnerability, reliability and risk', Prog. Struct. Eng. Mater., 2002, 4(2): 203-212.

[14]EM Melchers, AT Beck. Structural reliability analysis and prediction. 3rd ed. Chichester, UK: John Wiley \& Sons; 2018.

[15]A. Hebbouche, M. Bensaibi, H. Mroueh,Seismic Fragility Curves and Damage Probabilities of Concrete Gravity Dam Under Near-Far Faults Ground Motions, Structural Engineering International, 2019, DOI: 10.1080/10168664.2018.1531686

[16] J M Duncan, Factors of safety and reliability in geotechnical engineering. Journal of Geotechnical and Geo-environmental Engineering, ASCE,2000, 126(4):307-316.

[17]D. Val, F. Bljuger, and D. Yankelevsky, Optimization problem solution in reliability analysis of reinforced concrete structures, Computers \& Structures, 1996, 60(3): 351-355. 
[18]L Altarejos-García, I Escuder-Bueno, A Serrano-Lombillo and MG de MembrilleraOrtuño, Methodology for estimating the probability of failure by sliding in concrete gravity dams in the context of risk analysis. Structural safety, 2012, 36: 1-13.

[19] A Lupoi C Callari. A probabilistic method for the seismic assessment of existing concrete gravity dams. Structure and Infrastructure Engineering, 2012, 8(10): 985-998. 